\title{
Pengaruh Model Pembelajaran Kooperatif Tipe Team Game Tournament (Tgt) Terhadap Pembentukan Nilai-Nilai Kerjasama Dalam Pembelajaran Permainan Hoki
}

\author{
Desti Siti Khoiriah ${ }^{1}$ Yunyun Yudiana ${ }^{2}$ \\ Program Studi Pendidikan Jasmani Kesehatan dan Rekreasi \\ Fakultas Pendidikan Olahraga dan Kesehatan \\ Universitas Pendidikan Indonesia \\ desti.kitty@yahoo.com
}

\begin{abstract}
Abstrak
Penelitian ini dilatarbelakangi oleh pengamatan penulis mengenai kurangnya kerjasama pada saat pembelajaran permainan hoki berlangsung. Oleh karena itu penelitian ini bertujuan untuk mengetahui apakah model pembelajaran kooperatif tipe Team Game Tournament (TGT) Memberikan Pengaruh Terhadap Pembentukan Nilai-nilai Kerjasama Dalam Pembelajaran Permainan Hoki di SMAN 26 Garut.Metode yang digunakan adalah eksperimen, dengan menggunakan desain penelitian Pretest-Posttest Control Group Design.penelitian ini dilaksanakan di SMAN 26 Garut. Populasi dalam penelitian ini adalah siswa yang mengikuti ekstrakulikuler hokidi SMAN 26 Garut yang berjumlah sebanyak 40 orang ditetapkan dengan total sampling. Kemudian dibagi menjadi dua kelompok, kelompok eksperimen sebanyak 20 orang dan kelompok kontrol sebanyak 20 orang yang ditentukan secara random sederhana. Berdasarkan pengolahan dan analisis data diperoleh nilai signifikasinya adalah 4,39lebih besar dari 0,05 maka $H_{0}$ ditolak. Kesimpulan,model pembelajaran kooperatif tipe Team Game Tournament (TGT) dalam permainan hoki memberikan pengaruh terhadap pembentukan nilai-nilai kerjasama di SMAN 26 Garut.
\end{abstract}

Kata kunci : Model pembelajaran kooperatif tipe Team Game Tournament (TGT), permainan hoki, kerjasama. 


\section{PENDAHULUAN}

Olahraga hoki yang terdapat disekolah merupakan olahraga yang mengacu kepada system pendidikan, penambahan jam pelajaran di luar KBM atau biasa disebut dengan ekstrakulikuler yang secara tidak langsung memberikan suatu hiburan di luar waktu KBM yang tanpa mereka sadari. Dengan bermain, bersenang-senang dan tanpa aturan yang kaku siswa dapat mengikuti olahraga hoki dengan senang hati. Oleh karena itu hoki dapat pula bertujuan sebagai olahraga rekreasi. Namun tidak dapat di pungkiri siswa yang mengikuti olahraga hoki di sekolah dengan sungguh-sungguh dan antusias serta tingkat kemahirannya sudah baik, siswa tersebut dapat di arahkan kepada jalur prestasi. Jenis permainan hoki ini jika kita lihat jenis dan karakter dari permainannya hampir menyerupai sepak bola.

Hoki adalah permainan beregu yang terdiri atas 11 orang pemain untuk hoki lapangan (field hockey), 10 orang pemain dan 1 orang penjaga gawang. Dan 5 orang pemain untuk hoki ruangan (indoor hockey), 4 orang pemain dan 1 orang penjaga gawang. Hoki adalah olahraga yang menggunakan alat berupa stik (tongkat pemukul) dan bola untuk pemain serta leguard untuk penjaga gawang yang terdiri atas helmet, pelindung dada, pelindung tangan kanan dan kiri, stik dan pelindung kaki dari ujung kaki (sepatu) hingga pelindung yang menutupi tungkai.

Teknik permainan hoki ini meliputi push (mendorong bola), hit (memukul bola), stop (menahan bola), dribble (menggiring bola), flick (mencungkil bola), jab (menjangkau bola), tackle (merampas bola) dan scoop (mengangkat bola) ke arah gawang lawan dengan tujuan agar tim dapat mencetak gol. Bola dinyatakan masuk jika pemain menyerang dan menembakan bola di dalam lingkaran serang atau lingkaran gawang lawan.

Kerjasama merupakan hal yang penting bagi kehidupan manusia, karena dengan kerjasama manusia dapat melangsungkan kehidupannya. Kerjasama juga menuntut interaksi antara beberapa pihak.Menurut Soerjono Soekanto (2006, hlm. 66) kerjasama merupakan suatu usaha bersama antara orang perorang atau 
kelompok untuk mencapai tujuan tertentu. Pendapat tersebut sudah jelas mengatakan bahwa kerjasama merupakan bentuk hubungan antara beberapa pihak yang saling berinteraksi untuk mencapai tujuan bersama.

Untuk meningkatkan kerjasama siswa perlu diajarkan keterampilan social. Hal ini dikarenakan dengan keterampilan sosial nilai-nilai dalam kerjasama akan terinternalisasi dalam diri siswa dengan cara pembiasaan. Keterampilan sosial yang harus dimiliki siswa untuk meningkatkan kemampuan kerjasama siswa diungkapkanSuherman (2001, hlm. 86) menyebutkan unsur penting dalam kerjasama adalah:

1) Mengikuti aturan

2) Membantu teman yag belum bisa

3) Ingin semua teman bermain dan berhasil

4) Memotivasi orang lain

5) Bekerja keras menerapkn skill

6) Hormat terhadap orang lain

7) Mengendalikan tempramen

8) Memperhatikan perasaan orang lain

9) Kerjasama meraih tujuan

10) Menerima pendapat orang lain

11) Bermain secara terkendali

Menurut Suprijono (2010, hlm. 46) model pembelajaran ialah pola yang digunakan sebagai pedoman dalam merencanakan pembelajaran dikelas maupun tutorial. Model pembelajaran mengacu pada pendekatan yang akan digunakan, termasuk didalamnya tujuan-tujuan pembelajaran, tahap-tahap dalam kegiatan pembelajaran, lingkungan pembelajaran, dan pengelolaan kelas. Melalui model pembelajaran, guru dapat membantu peserta didik mendapatkan informasi, ide, keterampilan, cara berfikir, dan mengekspresikan ide. Model pembelajaran berfungsi pula sebagai pedoman bagi para perancang pembelajaran dan para guru dalam merencanakan aktivitas belajar mengajar.

Banyak model pembelajaran yang dapat digunakan agar terbentuknya kerjasama pada siswa. Disini peneliti mengambil model pembelajaran kooperatif tipe team game tournament (TGT) karena,Menurut Rusman (2010, hlm. 224), TGT adalah salah satu tipe pembelajaran kooperatif yang menempatkan siswa 
dalam kelompok-kelompok belajar yang beranggotakan 4 sampai 6 orang siswa yang memiliki kemampuan, jenis kelamin, suku kata atau ras yang berbeda. Menurut Slavin (2008) pembelajaran kooperatif tipe TGT terdiri dari lima langkah tahapan, yaitu tahap penyajian kelas (class precentation), belajar dalam kelompok (teams), permainan (games), pertandingan (tournament), dan penghargaan kelompok (team recognition).

\section{METODE}

Terdapat beberapa metode yang dapat digunakan untuk memecahkan suatu permasalahan.Metode yang digunakan dalam penelitian ini adalah metode eksperimen, dimana metode eksperimen ini merupakan penelitian yang dilakukan dengan mengadakan manipulasi terhadap objek penelitian serta adanya kontrol (Nazir, 2005, hlm. 63). Hal ini sejalan dengan yang dikatakan oleh Sugiyono (2011, hlm. 108) bahwa "metode penelitian eksperimen digunakan untuk mencari pengaruh perlakuan tertentu terhadap yang lain dalam kondisi yang terkendali. Jadi dapat disimpulkan bahwa metode penelitian eksperimen bertujuan untuk menyelidiki ada tidaknya atau seberapa besar hubungan sebab akibat dengan memberikan perlakuan-perlakuan tertentu pada suatu kelompok eksperimental dan menyediakan kontrol untuk perbandingan.

Adapun populasi dalam penelitian ini adalah siswa SMA Negeri 26Garut yang mengikuti ekstrakurikuler hoki yang berjumlah 40 orang siswa yang terdiri dari 20 orangsebagai kelompok eksperimen dan 20 orang siswasebagai kontrol sampelnya.

Untuk memperoleh data secara objektif, diperlukan instrumen yang tepat sehingga masalah yang diteliti akan terefleksi dengan baik. Instrumen yang digunakan dalam penelitian ini yaitu menggunakan instrument kuisioner atau angket dan lembar observasi kerjasama siswa. 
Tabel 1

Kategori Penilaian dengan Menggunakan Skala Likert untuk Angket

\begin{tabular}{|c|c|c|}
\hline \multirow{2}{*}{$\begin{array}{c}\text { Alternatif } \\
\text { Jawaban }\end{array}$} & \multicolumn{2}{|c|}{ Skor Alternatif Jawaban } \\
\cline { 2 - 3 } & Positif & Negatif \\
\hline SS & 5 & 1 \\
S & 4 & 2 \\
R & 3 & 3 \\
TS & 2 & 4 \\
STS & 1 & 5 \\
\hline
\end{tabular}

Tabel 2

Kategori Penilaian dengan Menggunakan Skala Likert untuk Lembar Observasi

\begin{tabular}{|c|c|}
\hline Sangat Baik & $\mathbf{4}$ \\
\hline Baik & 3 \\
\hline Tidak Baik & 2 \\
\hline Sangat Tidak Baik & 1 \\
\hline
\end{tabular}

\section{a. Kisi-kisi Angket Kerjasama Bentuk Angket}

Menurut Polak M. (1985) dalam Sumardiyanto, dkk (2010, hlm. 123), kerjasama atau kooperasi (cooperation) adalah gejala saling mendekati untuk mengurus kepentingan bersama dan tujuan bersama.

1. Mengikuti aturan

2. Membantu teman yang belm bisa

3. Ingin semua teman bermain dan berhasil

4. Memotivasi orang lain

5. Bekerja keras menerapkan skill

6. Mengendalikan tempramen

7. Memperhatikan perasaan orang lain

8. Tidak egois 


\section{a. Kisi-kisi Kerjasama dalam Bentuk Lembar Observasi}

Kisi-kisi angket penelitian ini diambil dari pendapat Suherman (2001, hlm. 86) bahwa unsur penting dalam kerjasama, yaitu:

a. Mengikuti aturan

b. Membantu teman yang belum bisa

c. Ingin semua teman bermain dan berhasil

d. Memotivasi orang lain

e. Bekerja keras menerapkn skill

f. Hormat terhadap orang lain

g. Mengendalikan tempramen

h. Memperhatikan perasaan orang lain

i.Kerjasama meraih tujuan

j.Menerima pendapat orang lain

k. Bermain secara terkendali

\section{HASIL DAN PEMBAHASAN}

a. Uji Normalitas

Tabel 3

HasilUji Normalitas Angket dan Observasi pada Kelompok Eksperimen dengan Kelompok

\begin{tabular}{|l|c|c|c|c|}
\hline \multicolumn{2}{|c|}{ Sampel } & $\begin{array}{c}\text { Lo } \\
L_{\text {hitung }}\end{array}$ & $\mathbf{L}_{\text {tabel }}$ & Kesimpulan \\
\hline $\begin{array}{l}\text { Kelompok } \\
\text { Eksperimen }\end{array}$ & Gain & 0.17 & 0.19 & NORMAL \\
\hline $\begin{array}{l}\text { Kelompok } \\
\text { Kontrol }\end{array}$ & Gain & 0.18 & 0.19 & NORMAL \\
\hline
\end{tabular}

Berdasarkan tabel 4.2 diatas dapat diketahui nilai $\mathrm{L}_{\text {tabel }}$ untuk tes pada kerjasama dari daftar sebesar 0,19. Nilai $L_{\text {hitung }}$ pada kelompok eksperimen adalah 0.17. Sedangkan nilai $L_{\text {hitung }}$ pada kelompok kontrol adalah 0.18 . Kriteria pengujian hipotesisnya adalah: Terima hipotesis nol $\left(\mathrm{H}_{0}\right)$ jika $\mathrm{L}_{\text {hitung }}$ lebih kecil dari pada $\mathrm{L}_{\text {tabel}}$, dalam hal lainnya hipotesis nol diterima. Dengan demikian data pada kerjasama kedua kelompok sampel berdistribusi normal. 
b. Uji Homogenitas

Tabel 4

Hasil Uji Homogenitas Gabungan Angket dan Observasi Dari Kelompok Eksperimen dan Kelompok Kontrol

\begin{tabular}{|c|c|c|c|}
\hline Sampel & $\mathbf{F}_{\text {hitung }}$ & $\mathbf{F}_{\text {tabel }}$ & Kesimpulan \\
\hline $\begin{array}{c}\text { Kelompok } \\
\text { Eksperimenl } \\
\text { dan } \\
\text { Kelompok } \\
\text { Kontrol }\end{array}$ & 1.46 & 2.15 & HOMOGEN \\
\hline
\end{tabular}

Berdasarkan penghitungan uji homogenitas pada kerjasama kelompok siswa pada kelompok eksperimen dan kelompok kontrol pada kerjasama diperoleh $\mathrm{F}_{\text {hitung }} 1.46$ dan pada $\mathrm{F}_{\text {tabel }}$ dengan taraf nyata $\alpha=0.05$ dengan $\mathrm{dk}$ pembilang $=\mathrm{n}$ 1=20-1=19 dan dk penyebut =n-1=20-1=19 menunjukan nilai 2.15 dengan kriteria

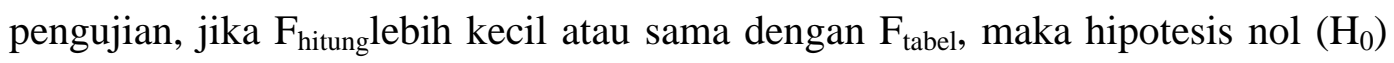
diterima. Dari perhitungan diatas, harga $\mathrm{F}_{\text {hitung }}$ lebih kecil dari $\mathrm{F}_{\text {tabel }}$ yang berarti bahwa data kerjasama memiliki varians sama atau homogen.

c. Uji Hipotesis

\section{Tabel 5}

Hasil Uji Hipotesis Gabungan Angket dan Observasi Dari Kelompok Eksperimen dan Kelompok Kontrol

\begin{tabular}{|c|c|c|c|}
\hline Jenis Tes & $\mathbf{t}_{\text {hitung }}$ & $\mathbf{t}_{\text {tabel }}$ & Keterangan \\
\hline $\begin{array}{c}\text { Pre-test } \\
\text { dan } \text { Post- } \\
\text { test }\end{array}$ & 4.39 & 2.021 & SIGNIFIKAN \\
\hline
\end{tabular}

Langkah-langkah pengujian Hipotesis

a. Diketahui :

Kelas Eksperimen : Kelas Kontrol :

$$
\begin{aligned}
& X_{1}: 24,9 \quad X_{2} \quad: 20,9 \\
& \alpha \quad: 0.05 \\
& n_{1}: 20 \quad n_{2}: 20
\end{aligned}
$$


$S_{1}^{2}: 3,16 \quad S_{2}^{2} \quad: 2,61$

b. Membuat hipotesis dalam bentuk :

$H_{0}$ : Tidak terdapat perbedaan pengaruh yang signifikan antara model pembelajaran konvensional terhadap hasil belajar siswa

$H_{1}$ : Terdapat perbedaan pengaruh yang signifikan antara model pembelajaran eksperimen dengan model pembelajaran konvensional terhadap hasil belajar siswa

c. Membuat hipotesis statistic

$H_{0}: \mu=\mu$

$H_{1}: \mu \neq \mu_{0}$

d. Mencari $t_{\text {hitung }}$

$$
\begin{array}{rlrl}
t_{\text {hitung }}=\frac{x_{1-x_{2}}}{\sqrt[S]{\frac{1}{n_{1}+\frac{1}{n_{2}}}}} & \mathrm{~S}^{2}=\frac{\left(n_{1}-1\right) S_{1}^{2}+\left(n_{2}-1\right) S_{2}^{2}}{n_{1}+n_{2}-2} & =2,88 \\
& =\frac{24,9-20,9}{2,88} \sqrt{\frac{1}{20}+\frac{1}{20}} & & =\frac{(20-1) 3,16+(20-1) 2,61}{20+20-2} \\
& =\frac{4}{2,88(0,316)} & & =\frac{60,04+49,59}{38} \\
& =\frac{4}{0.91} & & =\frac{109,63}{38} \\
& =4,39 &
\end{array}
$$

e. Menentukan kriteria penerimaan dan penolakan hipotesis terima $H_{0}$ jika :

Terima $H_{0}$ jika $\mathrm{t}(1-1 / 2 \alpha)<\mathrm{t}<\mathrm{t}(1-1 / 2 \alpha)$

Dalam $H_{0}$ ditolak untuk $\alpha=0.05$ dan dk $(20+20-2)=38$, maka Hipotesis nilai t pada distribusi (siswa) sebesar 4,39.

f. Membandingkan $t_{\text {hitung }}$ dengan $t_{\text {tabel }}$

Ternyata nilai $t_{\text {hitung }}(4,39)$ dan $t_{\text {tabel }}(2,021)$, maka $H_{0}$ ditolak

g. Membuat kesimpulan

Terdapat perbedaan pengaruh yang signifikan terhadap model pembelajaran kooperatif tipe Team Game Tournament (TGT) terhadap 
pembentukan nilai-nilai kerjasama siswa dalam pembelajaran permainan hoki.

\section{DISKUSI PENEMUAN}

Setelah dilakukan pengolahan dan analisis data melalui uji statistik, maka penulis mendapatkan gambaran mengenai "Pengaruh Model Pembelajaran Kooperatif Tipe Team Game Tournament (TGT) terhadap Pembentukan Nilainilai Kerjasama dalam Pembelajaran Permainan Hoki di SMA Negeri 26 Garut.

Berdasarkan data yang diperoleh, dan analisis data yang telah dilakukan tentang pengaruh model pembelajaran kooperatif tipe Team Game Tournament (TGT) dalam permainan hoki terhadap pembentukan nilai-nilai kerjasama siswa, maka terlihat bahwa pembelajaran kooperatif tipe Team Game Tournament (TGT) berpengaruh terhadap pembentukan nilai-nilai kerjasama siswa SMA Negeri 26 Garut.

Dari diskusi penemuan yang telah dipaparkan tersebut, peneliti dapat memberikan gambaran bagi para pembina, pembaca, serta guru pendidikan jasmani bahwa pembelajaran dengan model pembelajaran kooperatif tipe Team Game Tournament (TGT) merupakan salah satu metode yang dapat diterapkan pada proses pembelajaran pendidikan jasmani, khususnya permainan hoki dan olahraga-olahraga permainan lainnya, dikarenakan pembelajaran kooperatif tipe Team Game Tournament (TGT) membantu mengembangkan dan meningkatkan kemampuan bermain hoki, serta membentuk kerjasama siswa dengan kegiatankegiatan pembelajaran yang variatif dan menyenangkan. Dengan demikian pembelajaran kooperatif tipe Team Game Tournament (TGT) dapat memberikan hasil yang signifikan terhadap kemampuan bermain hoki dan pembentukan kerjasama siswa. 


\section{KESIMPULAN}

Berdasarkan hasil pengolahan dan analisis data yang di paparkan dalam bab IV dapat disimpulkan bahwa: Model pembelajaran kooperatif tipe Team Game Tournament (TGT) dalam permainan hoki memberikan pengaruh terhadap Pembentukan nilai-nilai kerjasama siswa di SMANegeri26Garut. 


\section{DAFTAR PUSTAKA}

Carsiwan, et al. (2013).PembelajaranPermainanHoki. Edisikedua. Bandung: CV. BintangWarliArtika.

Dr. Bambang Abdljabar, M.Pd. \& Jajat Darajat KN, S.Pd., M.kes., AIFO. (2013) Aplikasi Statistika Dalam Penjas.Edisi kedua. Bandung.

Pandjaitan. (1992). Pengertian Ekstrakurikuler. Diakses dari http://www.raseko.com/2013/05/pengertian-kegiatan-ekstrakurikuler.htm.

Sumardiyanto, dkk. (2010). Sejarah dan Filsafat Olahraga. FPOK UPI Bandung.

Sugiyono, (2012). Metode Penelitian Pendidikan. Bandung. Alfabeta 